\title{
HUBUNGAN PENGETAHUAN DENGAN SIKAP PERAWAT DALAM PENCEGAHAN PASIEN JATUH DI RUANG RAWAT INAP RUMAH SAKIT
}

\author{
Rahmat $^{1}$, Nandang Jamiat Nugraha ${ }^{2}$, Yoghie Maroghie Jauhari ${ }^{3}$ \\ ${ }^{1,2,3)}$ Universitas 'Aisyiyah Bandung \\ syifataini.sastro17@gmail.com
}

\begin{abstract}
ABSTRAK
Prevalensi pasien jatuh di rumah sakit selama proses perawatan tahun 2017 mengalami kenaikan 45,7\% dari tahun 2016. Berdasarkan data Dinas Kesehatan Kota Bandung terdapat $5,7 \%$ dari total rumah sakit belum mencapai standar dalam pencegahan risiko jatuh yang mengakibatkan cedera dan kematian pasien. Penelitian ini bertujuan untuk mengetahui hubungan pengetahuan dengan sikap perawat dalam pencegahan pasien jatuh di ruang rawat inap Rumah Sakit Bhayangkara Sartika Asih Bandung. Desain penelitian yang digunakan kuantitatif analitik dengan rancangan cross sectional dengan sampel total. Responden yang berpartisipasi adalah 66 perawat yang berkerja di ruang rawat inap. Analisis data menggunakan uji spearman rank correlation. Hasil penelitian menunjukkan bahwa pengetahuan diet dengan kategori cukup (48,5\%), sikap positif dan negatif sama yaitu (50\%) dengan p-value 0,008. Dapat disimpulkan bahwa terdapat hubungan pengetahuan dengan sikap perawat dalam pencegahan pasien jatuh di ruang rawat inap Rumah Sakit Bhayangkara Sartika Asih Bandung. Saran yang dapat diberikan untuk rumah sakit agar dapat memberikan pelatihan yang menyeluruh pada setiap tenaga kerja dalam pencegahan pasien jatuh.
\end{abstract}

Kata kunci : pencegahan pasien jatuh, pengetahuan, sikap

\begin{abstract}
The prevalence of falling patients in hospitals get during treatment in 2017 increased by 45.7\% from 2016, the data from Public Health Service in Bandung were 5.7\% of the total hospitals have not reached the standard in preventing the risk of falling where the fall incident resulted in injury until patient's death. This study aimed to determine the relationship of knowledge with nurse attitudes in preventing falling patients in the Inpatient Room at Bhayangkara Sartika Asih Hospital in Bandung. The research design used quantitative analytic with cross sectional design with a total sample. Participating respondents were 66 nurses who worked in the inpatient room. The data analysis also used the Spearman rank correlation test. The results showed that knowledge of the diet with sufficient categories (48.5\%), positive and negative attitudes were the same (50\%) with a p-value of 0.008. It can be concluded that there is a relationship of knowledge with nurses attitude in preventing falling patients in the Inpatient Room of Bhayangkara Sartika Asih Hospital, Bandung. The advice which can be given to hospitals to be able to provide comprehensive training and super vision to each workforce in terms of preventing falling patients.
\end{abstract}

Keywords: attitude, knowledge, prevention of falling patients 


\section{PENDAHULUAN}

Fakta temuan World Health Organization (WHO) yang dipublikasi pada tahun 2018 menyatakan bahwa keselamatan pasien adalah masalah global, 1:300 pasien berisiko cedera bahkan sampai kematian selama perawatan, Salah satu penyebabnya adalah kejadian jatuh pada pasien di rumah sakit yang berhubungan dengan kelalaian tenaga kesehatan dalam antisipasi pencegahan jatuh (WHO, 2018). Kongres Perhimpunan Rumah Sakit Seluruh Indonesia (PERSI) di Indonesia dalam kurun waktu 8 bulan terjadi insiden jatuh pada pasien sebesar 14\% dari jumlah pasien yang berobat ke rumah sakit dan menjadi 5 besar insiden kesalahan medis (Trisnawati, 2018). Berdasarkan data dari Dinas Kesehatan Kota Bandung terdapat 5,7\% dari total rumah sakit belum mencapai standar dalam pencegahan risiko jatuh (Dinkes, 2019). Untuk mengantisipasi kejadian pasien jatuh maka kementerian kesehatan menetapkan peraturan nomor 11 tahun 2017 tentang keselamatan pasien dan dalam Standar Nasional Akreditasi Rumah Sakit edisi 1 . Tindakan pencegahan yaitu perawat melakukan pendidikan kesehatan kepada pasien dan keluarga mengenai pencegahan jatuh dengan penggunaan alat bantu, penanda dan pengaman, pencegahan dengan melakukan perlindungan dengan mengenakan gelang atau label serta menggunakan fasilitas keselamatan dan menjaga kondisi lingkungan pasien tetap aman, Selanjutnya, melakukan asesmen sedini mungkin pada pasien dengan Morse Fall Scalel Humpty Dumpty, serta melakukan penanganan pada pasien jatuh tergantung jenis cedera dan rehabilitasi agar kondisi kesehatan pasien dapat tercapai secara optimal dan meminimalkan kecacatan akibat jatuh (Fiona, 2015). Penelitian (Devi, 2016) yang meneliti pengetahuan perawat terhadap penerapan keselamatan pasien didapatkan hasil pengetahuan yang dominan pada perawat pelaksana yaitu hanya sampai cukup sebanyak $43 \%$ dan untuk pelaksanaan keselamatan pasien dalam kategori kurang baik sebesar 64,2\%, Penelitian Najihah 13,6\% perawat berpotensi terhadap insiden keselamatan pasien karena jatuh yaitu $48,8 \%$ dan $88 \%$ kejadian tersebut tidak dilaporkan oleh perawat karena sikap perawat yang cenderung menyepelekan insiden jatuh (Najihah, 2018). Tujuan dari penelitian ini adalah untuk mengetahui hubungan pengetahuan dengan sikap perawat dalam pencegahan pasien jatuh di ruang rawat inap Rumah Sakit Bhayangkara Sartika Asih Bandung.

\section{METODOLOGI}

Desain penelitian ini menggunakan kualitatif analitik dengan pendekatan cross sectional. Populasi penelitian ini adalah perawat yang bertugas di ruang rawat inap Rumah Sakit Bhayangkara SartikaAsih Bandung. pengambilan sampel menggunakan sampel total dengan 66 perawat yang bersedia menjadi responden. Instrumen yang digunakan adalah kuesioner yang telah di uji validitas dan reliabilitasnya yaitu 21 soal pengetahuan dan 23 soal sikap. Analisis data menggunakan uji spearman rank correlation. Penelitian ini telah diuji oleh Komite Etik STIKes 'Aisyiyah Bandung nomor 14/ KEP.02/STIKes-AB/VII/2019.

\section{HASIL}

\section{Distribusi Frekuensi Karakteristik} Perawat di Ruang Rawat Inap Rumah Sakit Bhayangkara Sartika Asih Bandung $(\mathrm{n}=66)$

Tabel 1. Distribusi Frekuensi Karakteristik Perawat di Ruang Rawat Inap Rumah Sakit Bhayangkara Sartika Asih Bandung $(\mathrm{n}=66)$ 


\begin{tabular}{lcc}
\hline \multicolumn{1}{c}{ Karakteristik } & f & \% \\
\hline Jenis kelamin & & \\
Laki-laki & 21 & 31,8 \\
Perempuan & 45 & 68,2 \\
Umur & & \\
20-29 Tahun & 39 & 59,1 \\
30-39 Tahun & 23 & 34,8 \\
40-50Tahun & 4 & 6,1 \\
Lama kerja & & \\
$<3$ Tahun & 24 & 36,4 \\
3-5 Tahun & 14 & 21,2 \\
6-10 Tahun & 18 & 27,3 \\
>10 Tahun & 10 & 15,2 \\
Pendidikan & & \\
DIII & 33 & 50,0 \\
Ners & 33 & 50,0 \\
Pengalaman & & \\
Pelatihan & & \\
Pernah & 38 & 57,6 \\
Tidak pernah & 28 & 42,4 \\
\hline
\end{tabular}

Tabel di atas menunjukkan data bahwa responden didominasi berjenis kelamin perempuan 45 orang $(68,2 \%)$, umur yang dominan 20-29 tahun yaitu 39 orang (59,1\%), lama kerja kurang dari 3 tahun 24 orang $(36,4 \%)$, pendidikan terakhir Ners sebanyak 33 orang (50\%), dan pengalaman pelatihan keselamatan pasien yang pernah mengikuti 38 orang $(57,6 \%)$.

2. Distribusi Frekuensi Pengetahuan perawat dalam pencegahan jatuh pada pasien rawat inap Rumah Sakit Bhayangkara Sartika Asih Bandung $(n=66)$

Tabel 2. Distribusi Frekuensi Pengetahuan Perawat dalam Pencegahan Jatuh pada Pasien Rawat Inap Rumah Sakit Bhayangkara Sartika Asih Bandung ( $n=66)$. di Ruang Rawat Inap Rumah Sakit

\begin{tabular}{ccc}
\hline Pengetahuan & f & \% \\
\hline Baik & 5 & 7,6 \\
Cukup & 32 & 48,5 \\
Kurang & 29 & 43,9 \\
\hline Jumlah & 66 & 100 \\
\hline
\end{tabular}

Tabel di atas menunjukkan bahwa pengetahuan perawat berada pada katagori cukup yaitu 32 responden (48,5\%), dalam katagori kurang yaitu 29 responden (43,9\%) dan katagori baik sebanyak 5 responden (7,6\%). Dari data tersebut diketahui katagori pengetahuan perawat di ruang rawat inap Rumah Sakit Bhayangkara Sartika Asih Bandung yang paling dominan berada pada katagori cukup yaitu 32 responden (48,5\%).

3. Distribusi Frekuensi Sikap Perawat dalam Pencegahan Pasien Jatuh di Ruang Rawat Inap Rumah Sakit Bhayangkara Sartika Asih Bandung $(n=66)$

Tabel 3. Distribusi Frekuensi Sikap Perawat dalam Pencegahan Pasien Jatuh di Ruang Rawat Inap Rumah Sakit Bhayangkara Sartika Asih Bandung $(n=66)$

\begin{tabular}{ccc}
\hline Sikap & f & \% \\
\hline Positif & 33 & 50,0 \\
Negatif & 33 & 50,0 \\
\hline Jumlah & 66 & 100 \\
\hline
\end{tabular}

Tabel di atas menunjukkan bahwa sikap perawat berada pada katagori positif berjumlah 33 responden $(50,0 \%)$ dan katagori negatif berjumlah 33 responden (50,0\%). Dari data tersebut disimpulkan bahwa sikap perawat yang bekerja di ruang rawat inap Rumah Sakit Bhayangkara Sartika Asih Bandung memiliki katagori yang sama antara sikap positif dan negatif dalam pencegahan pasien jatuh di ruang 
rawat inap.

4. Tabulasi Silang Pengetahuan dengan Sikap Perawat dalam Pencegahan Pasien Jatuh di Ruang Rawat Inap Rumah Sakit Bhayangkara Sartika Asih Bandung (n=66)

Tabel 4. Tabulasi Silang Pengetahuan dengan Sikap Perawat dalam Pencegahan Pasien Jatuh di Ruang Rawat Inap Rumah Sakit Bhayangkara Sartika Asih Bandung (n=66)

\begin{tabular}{|c|c|c|c|c|c|c|c|}
\hline \multirow{3}{*}{ Pengetahuan } & \multicolumn{4}{|c|}{ Sikap } & \multirow{2}{*}{\multicolumn{2}{|c|}{ Total }} & \multirow{3}{*}{ p value } \\
\hline & \multicolumn{2}{|c|}{ Positif } & \multicolumn{2}{|c|}{ Negatif } & & & \\
\hline & f & $\%$ & $\mathbf{f}$ & $\%$ & f & $\%$ & \\
\hline Baik & 5 & 7,6 & 0 & 0 & 5 & 7,6 & \\
\hline Cukup & 18 & 27,3 & 14 & 21,2 & 32 & 48,5 & 0,008 \\
\hline Kurang & 10 & 15,2 & 19 & 28,8 & 29 & 43,9 & \\
\hline Total & 33 & 50 & 33 & 50 & 66 & 100 & \\
\hline
\end{tabular}

Dari tabel tabulasi silang di atas ditunjukkan bahwa perawat yang memiliki pengetahuan baik dan sikap positif sebanyak 5 responden $(7,6 \%)$, perawat yang memiliki pengetahuan baik dan memiliki sikap negatif tidak ada $(0 \%)$, perawat yang memiliki pengetahuan cukup dan memiliki sikap positif sebanyak 18 responden (27,3\%), perawat yang memiliki pengetahuan cukup dan sikap negatif sebanyak 14 responden (21,2\%), perawatyangmemiliki pengetahuan kurang dan sikap positif sebanyak 10 responden $(15,2 \%)$, perawat yang memiliki pengetahuan kurang dan memiliki sikap negatif sebanyak 19 responden (28,8\%). Hasil analisis uji hubungan didapatkan nilai p-value $=0,008$, jadi ada hubungan antara pengetahuan dengan sikap perawat dalam pencegahan pasien jatuh di ruang rawat inap Rumah Sakit Bhayangkara Sartika Asih Bandung.

\section{PEMBAHASAN}

Pencegahan pasien jatuh merupakan upaya untuk menghindarkan atau meminimalkan pasien dari bahaya cedera akibat terjatuh selama proses perawatan. Upaya tersebut harus dilandasi dengan pengetahuan dan didukung dengan sikap seorang perawat (Purba,2013). Faktor-faktor yang memengaruhi tingkat pengetahuan menurut Notoatmodjo (2014) antara lain: pendidikan, informasi, pengalaman, usia. Menurut Azwar (2013) faktor-faktor yang memengaruhi sikap antara lain: pengalaman pribadi, pengaruh orang lain yang dianggap penting, pendidikan, faktor emosional. Sehubungan dengan beberapa faktor tersebut saling berkaitan maka dalam penelitian ini faktor tersebut dimasukan dalam data demografi atau karakteristik responden yang terdiri atas: umur, jenis kelamin, pendidikan terakhir, pengalaman mengikuti pelatihan keselamatan pasien, dan lama berkerja.

Dari hasil penelitian yang telah dilakukan pada 66 responden diketahui rentang pengetahuan perawat di ruang rawat inap Rumah Sakit Bhayangkara Sartika Asih Bandung yang paling dominan berada pada katagori cukup yaitu sebanyak 32 responden (48,5\%). Pengetahuan perawat dalam penelitian ini juga masih dalam katagori cukup, Hal tersebut disebabkan oleh sikap perawat yang bekerja kurang memiliki kesadaran tinggi pentingnya menggali ilmu dan informasi tentang keselamatan pasien terutama pencegahan jatuh pada pasien melalui media masa atau media elektronik dan masih terpaku pada pelatihan yang diikutinya, Selain itu, 
pelatihan mengenai pencegahan pasien jatuh belum diikuti oleh semua perawat.

Pengetahuan perawat bisa pula dipengaruhi oleh kebanyakan perawat yang memiliki masa kerja kurang dari 3 tahun. Dalam kurun waktu tersebut perawat masih minim dari segi pengalaman kerja atau dinilai memiliki pengetahuan yang belum matang, sedangkan pengalaman sangat menunjang pengetahuan dalam pencegahan pasien jatuh di ruang rawat inap, Notoatmodjo (2014) menyatakan bahwa semakin banyak pengalaman maka semakin baik juga pengetahuan yang dimiliki seseorang dan pekerjaan memudahkan seseorang untuk mengakses informasi pada bidangnya, Jadi semakin lama seseorang bekerja semakin baik juga pengetahuan pada bidang pekerjaannya.

Pengetahuan perawat dalam penelitian ini juga dipengaruhi oleh umur perawat yang masih terbilang dewasa awal yaitu 20-29 tahun. Pengalaman minim dan umur juga memengaruhi daya tangkap belajar seseorang. Walaupun sebagian besar perawat berpendidikan tinggi (Ners) tetapi seperti yang dikatakan Notoatmodjo bahwa pendidikan akademik bukan menjadi patokan atau tolok ukur seseorang memiliki pengetahuan yang selalu baik. Adapun faktor umur merupakan faktor yang berpengaruh pada pengetahuan karena semakin bertambah umur semakin baik juga daya tangkap dan penerimaan seseorang pada ilmu yang di dapat (Notoatmodjo, 2014).

Hasil penelitian yang telah dilakukan pada 66 responden yang bekerja di ruang rawat inap rumah sakit Bhayangkara Sartika Asih Bandung didapatkan sikap perawat berada pada rentang yang sama yaitu 33 (50\%) memiliki sikap positif dan 33 (50\%) memiliki sikap negatif. Sikap merupakan rangkaian dari proses-proses kognitif, afektif dan perilaku. Secara garis besar kognitif dihubungkan dengan pembelajaran, afektif berhubungan dengan emosi, dan perilaku berhubungan dengan tingkah laku. (Notoatmodjo, 2014). Hasil penelitian ini didapatkan sikap perawat $50 \%$ masih negatif dapat disebabkan oleh pengalaman dan faktor emosional. Perawat masih dalam rentang lama kerja yang kurang dari 3 tahun, umur dalam rentang dewasa awal, pelatihan yang belum diikuti oleh semua perawat, sebagian besar perawat berjenis kelamin perempuan yang memiliki regulasi emosi berbeda dibanding laki-laki yaitu kurang dapat menyembunyikan perasaan dalam kegiatan kerja atau kehidupan sehari-hari (Prasetyo, 2017).

Hasil uji hubungan antara pengetahuan dengan sikap perawat tentang pencegahan pasien jatuh di ruang rawat inap Rumah Sakit Bhayangkara Sartika Asih Bandung diperoleh nilai $p$-value $0,008 \leq 0,05$ maka keputusan yang didapat adalah $\mathrm{H}_{0}$ ditolak atau $\mathrm{Ha}$ diterima. Kesimpulannya adalah ada hubungan antara pengetahuan dengan sikap perawat dalam pencegahan pasien jatuh di ruang rawat inap Rumah Sakit Bhayangkara Sartika Asih Bandung.

Penelitian ini sejalan dengan pedapat Listianawati (2018) yang menunjukkan bahwa adanya hubungan pengetahuan dengan tindakan penerapan patient safety, Pengetahuan yang baik dapat menghasilkan tindakan yang baik juga. Hasil analisis bivariat diperoleh nilai $p$-value $=$ 0,002 yang menunjukkan p-value lebih kecil dari $\hat{\mathrm{I}} \pm=0,05$ maka $\mathrm{Ha}$ diterima dan $\mathrm{Ho}$ ditolak. Ada hubungan yang signifikan antara pengetahuan perawat tentang keselamatan pasien (patient safety) dengan sikap perawat terhadap pemberian obat di ruang rawat inap kelas III RSUD dr. Loekmono Hadi Kudus. Keberhasilan tindakan perlu didukung adanya kepatuhan pribadi perawat tersebut sehingga para perawat diharapkan dapat meningkatkan kepatuhan tindakan sesuai dengan standar operasional prosedur dalam pencegahan pasien (Listianawati, 2018).

Begitu pula dengan penelitian ini, hasil 
tabulasi silang bahwa perawat yang memiliki pengetahuan baik cenderung memiliki sikap yang positif dan perawat dengan pengetahuan cukup juga cenderung bersikap positif, sedangkan perawat yang memiliki pengetahuan kurang cenderung memiliki sikap yang negatif, yang berarti semakin baik pengetahuan ynag dimiliki seorang perawat maka sikap yang dimiliki perawat itu pun akan semakin baik sedangkan semakin kurang pengetahuan perawat maka sikap yang dimiliki pun juga akan semakin negatif. Seperti yang dikatakan oleh Fan \& Zhang (2018) pengetahuan adalah ilmu yang mendasari untuk memperkuat perubahan sikap dan sebagai pendorong perubahan perilaku/ tindakan. Sikap merupakan sebuah kecenderungan orang dalam membuat pilihan atau tindakan, Hal tersebut penting karena sikap yang positif akan memungkinkan seseorang menggali dan meneliti sesuatu sehingga memperkaya pengetahuannya. Pengetahuan dan sikap yang baik merupakan faktor utama yang berpengaruh terhadap tindakan yang berdampak jangka panjang terhadap perilaku pencegahan pasien jatuh (Ari, 2015). Jadi untuk menciptakan iklim perawatan kesehatan yang lebih aman terutama mencegah terjadinya jatuh pada pasien di ruang rawat inap maka diperlukan pengetahuan dan sikap yang adekuat.

\section{SIMPULAN DAN SARAN}

\section{Simpulan}

Ada hubungan pengetahuan dengan sikap perawat dalam pencegahan pasien jatuh di ruang rawat inap Rumah Sakit Bhayangkara Sartika Asih Bandung.

\section{Saran}

Hasil penelitian ini diharapkan bisa menjadi bahan kajian dan pertimbangan rumah sakit untuk membuat kebijakan seperti mengadakan pelatihan dan sosialisasi merata pada seluruh staf yang bekerja. Perawat bisa lebih mengembangkan rasa ingin tahu dan selalu meningkatkan pengetahuan dalam keselamatan pesien terutama pencegahan pasien jatuh dengan mengikuti pelatihan, maupun dengan menggali informasi via media elektronik dengan kesadaran sendiri, serta mematuhi standar oprasional prosedur yang telah ditetapkan oleh rumah sakit.

\section{DAFTAR PUSTAKA}

Afandi, N. (2017). Konsep Ilmu Pengetahuan,Sifat, dan Komponen Dasarnya. Jember: academia.edu.

Devi, D. (2016). Hubungan pengetahuan perawt dengan upaya penerapan pasient safety di ruang rawat inap rsud Dr.Zainal abidin Banda aceh. Ideal Nursing Journal, Vol. VII No.I.

Dinkes. (2019). Data Standar Pelayanan Minimum Pencegahan Cidera Akibat Jatuh Di Rumah Sakit. Bandung.

Fiona, F. (2015). 5 Level of Prevention (menurut Leavel and Clark) \& 4 Faktor yang Mempengaruhi Derajat Kesehatan Masyarakat (menurut Blum). https:// fitafiona.blogspot.com/2015/11/5-levelof-prevention-menurut-leavel.html.

Listianawati, R. (2018). Hubungan Pengetahuan Perawat Tentang Keselamatan Pasien (Patient Safety) Dengan Sikap Perawat Terhadap Pemberian Obat Di Ruang Rawat Inap Kelas Iii Rsud Dr. Loekmono Hadi Kudus. Prosiding HEFA (Health Events for All).

Manalu. (2018). Pengetahuan perawat tentang pencegahan pasien resiko jatuh di ruang rawat inap RSUD Dr.R.M Djoelham Binjai. USU Respiratori.

Marina, N. (2017). faktor-faktor yang berhubungan dengan pencegahan jatuh pada pasien resiko jatuh oleh perawat 
di ruang nusa indah RSUD Tugurejo Semarang. Jurnal kesehatan masyarakat vol.5.

Najihah. (2018). Budaya Keselamatan Pasien Dan Insiden Keselamatan Pasien Di Rumah Sakit. Jurnal Of Islamic Nursing. Notoatmodjo. (2014). Teori \& Pengukuran Pengetahuan, Sikap Dan Perilaku Manusia. Jakarta: Rineka Cipta.
Prasetyo. (2017). Gambaran upaya pencegahan risiko jatuh oleh perawat di ruang rawat inap RSUD Kajen Kabupaten Pekalongan. STIKes Muhammadiyah Pekajanan Pekalongan.

Trisnawati, D. (2018). Risk factors related to fall incident in hospitaliced. NurseLine Journal Vol.3 No.2.

WHO. (2018). 10 fact patients safety. who. 
